\title{
Should Echocardiographic Evaluation Be Performed Routinely in the First 72 Hours in Extremely Low Birth Weight Babies?
}

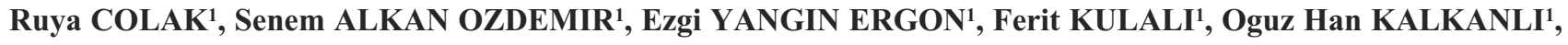 \\ Tulin Gokmen YILDIRIM1, Murat Muhtar YILMAZER ${ }^{2}$, Cuneyt ZIHNI², Sebnem CALKAVUR ${ }^{1}$
}

Izmir, Turkey

\begin{abstract}
OBJECTIVE: Hemodynamically significant patent ductus arteriosus is resulting in severe mortality and morbidity in infants with extremely low birth weight. In our study, we aimed to evaluate the necessity of performing routine echocardiography in the first 72 hours in extremely low birth weight infants.
\end{abstract}

STUDY DESIGN: This study was planned retrospectively. Between June 2016 and December 2018, 36 patients diagnosed with hemodynamically significant patent ductus arteriosus who were hospitalized in the neonatal intensive care unit, with $\leq 28$ gestational weeks or $\leq 1000 \mathrm{~g}$ were included in this study. These babies were routinely performed echocardiography for patent ductus arteriosus between 24-72 hours, although they were asymptomatic in the period from June 2016 to December 2017 ( $n=23)$. Between January 2018 and December 2018, patients without patent ductus arteriosus symptoms were expected to complete 72 hours for routine patent ductus arteriosus screening $(n=13)$. The patients were divided into 2 groups as the early echocardiography group $(n=23)$ and the late echocardiography group $(n=13)$. In the presence of at least one of the clinical signs of systemic hypo perfusion and/or pulmonary hyper perfusion, symptomatic patent ductus arteriosus was accepted and closure treatment was applied with ibuprofen $(n=23)$ or paracetamol $(n=5)$. While the two groups were compared in terms of demographic features, echocardiography findings, and the state of taking closure therapy, patients receiving closure therapy were compared in terms of mortality and premature morbidity.

RESULTS: The mean birth weight of 36 patients was $855 \pm 241 \mathrm{~g}$, and the mean gestational age was $26.4 \pm 2.1$ gestational weeks. It was observed that the two groups were similar in terms of demographic characteristics. Although the findings of echocardiography and treatment rates were similar between the two groups, it was observed that the echocardiography group had earlier closure treatment $(p=0.03)$. In patients receiving closure treatment, performing early $(n=17)$ and late $(n=11)$ echocardiography showed no statistical difference in the long-term results.

CONCLUSION: Performing early echocardiography without symptoms in infants with extremely low birth weight may provoke the clinician to give patent ductus arteriosus closure treatment earlier. In infants with extremely low birth weight, unnecessary closure treatment can be prevented by closely monitoring the symptoms of patent ductus arteriosus and performing echocardiography when necessary.

Keywords: Echocardiography, Extremely low birth weight infants, Hemodynamically significant patent ductus arteriosus

Gynecol Obstet Reprod Med 2021;27(2):175-180

\footnotetext{
${ }^{I}$ Izmir Health Science University Division of Neonatology, Dr. Behcet Uz Child Disease and Pediatric Surgery Training and Research Hospital, Izmir, Turkey

${ }^{2}$ Izmir Health Science University Division of Pediatric Cardiology, Dr. Behcet Uz Child Disease and Pediatric Surgery Training and Research Hospital, Izmir, Turkey

Address of Correspondence: Ruya Colak

Izmir Health Science University Division of Neonatology, Dr. Behcet Uz Child Disease and Pediatric Surgery Training and Research Hospital, Izmir, Turkey ruyacolak@hotmail.com

Submitted for Publication: 18.11.2020 Revised for Publication: 29.11.2020 Accepted for Publication: 07.01.2021 Online Published: 02.08.2021 ORCID IDs of the authors: $\quad$ RC: 0000-0002-8732-7932 SAO: 0000-0003-0474-7120 EYE: 0000-0003-0836-7379 FK: 0000-0003-0310-1184 OHK: 0000-0003-1965-1420 TGY: 0000-0001-5951-2631 MMY: 0000-0003-0819-5829 CZ: 0000-0001-6618-5368 SC: 0000-0002-3820-2690
}

\section{Introduction}

Patent ductus arteriosus (PDA) is a common condition in infants with extremely low birth weight (ELBW) and associated with mortality and morbidity such as intraventricular hemorrhage (IVH), necrotizing enterocolitis (NEC), and bronchopulmonary dysplasia (BPD). The gold standard diagnostic method used to detect the presence of PDA is echocardio-

\begin{tabular}{|c|c|}
\hline \multirow{3}{*}{ 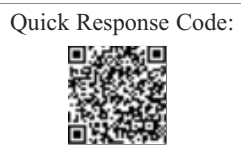 } & Access this article online \\
\hline & $\begin{array}{l}\text { Website: www.gorm.com.tr } \\
\text { e- mail: info@gorm.com.tr }\end{array}$ \\
\hline & DOI:10.21613/GORM.2020-1168 \\
\hline
\end{tabular}

How to cite this article: Colak R. Alkan Ozdemir S. Yangin Ergon E. Kulali F. Kalkanli OH. Yildirim TG. Yilmazer MM. Zihni C. Calkavur S. Should Echocardiographic Evaluation Be Performed Routinely in the First 72 Hours in Extremely Low Birth Weight Babies? Gynecol Obstet Reprod Med. $2021 ; 27(2): 175-180$ 
graphic (ECHO) imaging (1). Early diagnosis of hemodynamically significant PDA (hsPDA) that is associated with prophylactic closure or early closure treatment is included in many studies (2-6).

Around $80 \%$ of premature infants with $\leq 28$ gestational weeks (GW) are born with PDA, but we know that about 34\% of these patients have spontaneous closure in their PDA on the seventh day $(7,8)$. Even though the PDA has a greater association with morbidities, there is still indecision by clinicians as to whether they should treat a PDA, because spontaneous closure rates are high.

Some guidelines are suggesting early echocardiographic imaging and early closure treatment in infants with ELBW, as well as some studies recommending follow-up symptoms without echocardiographic imaging in the first week $(9,10)$. In this study, we aimed to investigate the necessity of performing ECHO in the first 72 hours for the diagnosis of PDA in infants with ELBW.

\section{Material and Method}

\section{Patients selection}

This study was planned as a retrospective study. $\leq 1000 \mathrm{~g}$ and/or $\leq 28 \mathrm{GW}$ babies who were admitted to Izmır Dr. Behcet Uz Children Hospital, Neonatal Intensive Care Unit (NICU) in the range of June 2016 to December 2018 were admitted in this study. Ethical approval from the Behcet Uz Child Hospital Ethics Committee (2019/306) was obtained and conformed to the tenets of the Declaration of Helsinki. The aims of the study were explained with an interpreter whenever necessary and written informed consent was obtained.

In our NICU, from June 2016 to January 2018, an approach to echocardiographic imaging was applied to infants with ELBW in the first 24-48 hours. During this period, 46 ELBW infants were admitted to NICU. One of them died before ECHO. Standard 2D ECHO was performed using a portable ECHO machine with a 6S-RS pediatric probe (Vivid e, GE Healthcare Clinical System) by the specialist pediatric cardiologist team of our hospital. For the diagnosis of hemodynamically significant PDA, at least one of these criteria was required: PDA diameter $>1.4 \mathrm{~mm}$, PDA diameter indexed to body surface area, left atrium to aorta ratio $>1.4$, a low-velocity ductal flow pattern, and diastolic flow reversal in the descending aorta, cerebral, mesenteric, and renal arteries (9-11). ECHO results were 15 of 45 patients had no PDA, 7 of them had not hsPDA, and 23 of them had hsPDA. These 23 patients with hsPDA were included in the study as group 1. Group 1 was called the Early ECHO Group (EEG) (Figure 1).

Between January 2018 and December 2018, patients without PDA symptoms were expected to complete 72 hours for routine PDA screening with ECHO. $\leq 1000 \mathrm{~g}$ and/or $\leq 28 \mathrm{GW}$ babies were 54, and four of them died without ECHO. All of them were $\leq 25 \mathrm{GW}$ and died in the first 24 hours due to severe respiratory distress syndrome (RDS). Early ECHO was performed in 2 of the remaining 50 patients due to hemodynamically instability. These patients were excluded from the study because these patients were given early ECHO. According to the ECHO results of 48 patients, 20 of them had no PDA, 15 of them did not have hsPDA, 13 of them had hsPDA. These 13 patients with hsPDA were included in the study as group 2 which was called the Late ECHO Group (LEG) (Figure 1).

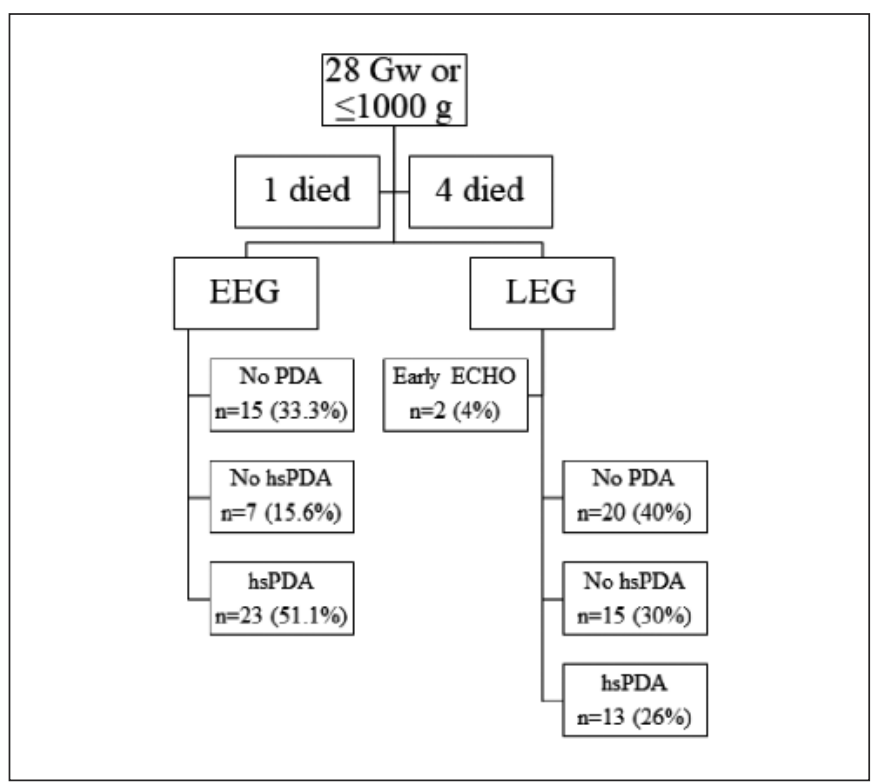

Figure 1: Design of patients included in the study

GW: Gestational weeks, EEG: Early ECHO group, PDA: Patent ductus arteriosus, ECHO:Echocardiography. hsPDA: Hemodynamically significant patent ductus arteriosus.

The exclusion criteria for the study were major congenital anomalies and congenital infections. Since there were no patients with these features, there was no patient excluded from this study.

\section{Treatment decisions and treatment choices for hsPDA}

Conservative treatment was applied to all patients diagnosed with hsPDA. The procedures for conservative treatment are listed below: a) Neutral thermal environment and adequate oxygenation, b) Increased positive end-expiratory pressure (PEEP $>5$ mbar) and short inspiration time $(0.30 \mathrm{sec}), \mathrm{c})$ Keeping the hematocrit level between $35-40 \%$, d) Adequate fluid treatment policy was implemented for the first seven days (9).

In the presence of at least one of the clinical findings of systemic hypo perfusion and/or pulmonary hyper perfusion, symptomatic PDA was accepted and closure treatment was applied with intravenous ibuprofen $(10 \mathrm{mg} / \mathrm{kg} / \mathrm{d}$ first day, 5 $\mathrm{mg} / \mathrm{kg} /$ day second and third days $)(\mathrm{n}=23)$ or intravenous paracetamol $(60 \mathrm{mg} / \mathrm{kg} /$ day - five days $)(\mathrm{n}=5)(12,13)$.

\section{Data collection}

While the two groups were compared in terms of demographic characteristics, ECHO findings, and the status of tak- 
ing closure treatment, patients receiving closure treatment were compared in terms of mortality and premature morbidity.

\section{Statistical analysis}

Statistical data were analyzed using the Statistical Package for the Social Sciences (SPSS) version 18.0 software (SPSS Inc., Chicago, IL, USA). Continuous variables were compared using Student's t-test or Mann-Whitney U test. Categorical variables were analyzed using the chi-square test or Fisher's exact test. A p-value of $<0.05$ was considered statistically significant.

\section{Study outcomes}

In this study, the primary outcome is to investigate the necessity of performing ECHO in the first 72 hours for the diagnosis of PDA in infants with ELBW. The secondary outcome is to compare the short and long-term results of patients treated early and late.

\section{Results}

During the study period, 100 preterm infants whose gestational age of $\leq 28 \mathrm{GW}$ and/or birth weight $\leq 1000 \mathrm{~g}$ were ad- mitted to NICU of which 36 infants were considered eligible for the study. While the rate of hsPDA was $51.1 \%$ in its EEG, this rate was $26 \%$ in its LEG (Figure 1). Five of 100 patients died without ECHO. The rate of hsPDA was determined in 36 (37.9\%) of 95 patients in total. The mean birth weight of 36 patients included in the study was $855 \pm 241 \mathrm{~g}$ (Mean \pm SD), and the gestational age was $26.4 \pm 2.1 \mathrm{GW}(\mathrm{Mean} \pm \mathrm{SD})$. Twentythree patients with EEG and 13 patients with LEG were similar in terms of demographic characteristics except for antenatal steroids (Table I). While antenatal steroid was made in $56.5 \%$ of patients with EEG, this rate was $15 \%$ in LEG and this difference was statistically significant $(p=0.016)$.

Although the ECHO findings and medical closure treatment rates of the two groups were similar, it was observed that earlier closure treatment was initiated in the EEG $(p=0.03)$ (Table II).

In patients receiving closure therapy, early $(n=17)$ and late $(n=11)$ ECHO did not show any statistical difference in the long-term results (Table III).

Table I: Comparison of demographic features of patients

\begin{tabular}{|c|c|c|c|}
\hline & $\begin{array}{c}\text { Early ECHO } \\
\text { Group (EEG) } \\
\quad n=23\end{array}$ & $\begin{array}{c}\text { Late ECHO } \\
\text { Group (LEG) } \\
\quad n=13\end{array}$ & $p$ \\
\hline Birth weight, g, median (IQR) & $795(360)$ & $1000(585)$ & 0.09 \\
\hline Gestational age, week, median (IQR) & $26(4)$ & $28(1)$ & 0.06 \\
\hline Gender, female, n (\%) & $11(47.8 \%)$ & $7(53.8 \%)$ & 0.72 \\
\hline Birth style, NSD, n (\%) & $6(26 \%)$ & $7(153.8 \%)$ & 0.09 \\
\hline Antenatal steroid, $\mathrm{n}(\%)$ & $13(56.5 \%)$ & $2(15.3 \%)$ & 0.016 \\
\hline Preeclampsia, n (\%) & $11(47.8 \%)$ & $5(38.4 \%)$ & 0.58 \\
\hline Gestational diabetes, n (\%) & $1(4.3 \%)$ & $1(7.6 \%)$ & 1 \\
\hline Premature rupture of membranes, $\mathrm{n}(\%)$ & $1(4.3 \%)$ & $2(15.3 \%)$ & 0.53 \\
\hline APGAR 1, median (IQR) & $5(1)$ & $7(0)$ & 0.07 \\
\hline APGAR 5, median (IQR) & $7(1)$ & $8(0)$ & 0.1 \\
\hline
\end{tabular}

ECHO: Echocardiography, EEG: Early ECHO group, LEG: Late ECHO group

Table II: Comparison of echocardiography findings and closure therapy status of patients

\begin{tabular}{|c|c|c|c|}
\hline & $\begin{array}{c}\text { Early ECHO } \\
\text { Group (EEG) } \\
\text { n=23 }\end{array}$ & $\begin{array}{l}\text { Late ECHO } \\
\text { Group (LEG) } \\
\quad n=13\end{array}$ & $p$ \\
\hline Ductus diameter, millimeter, mean $\pm S D$ & $1.73 \pm 0.65$ & $2.0 \pm 0.56$ & 0.15 \\
\hline Left atrium: Aorta ratio, mean $\pm S D$ & $1.38 \pm 0.2$ & $1.47 \pm 0.21$ & 0.67 \\
\hline Ductus diameter/birth weight, mean $\pm S D$ & $2.2 \pm 0.98$ & $2.34 \pm 0.94$ & 0.34 \\
\hline Receiving ductus closure therapy, $\mathrm{n}(\%)$ & $17(73.9 \%)$ & $11(84.6 \%)$ & 0.45 \\
\hline Day of receiving PDA closure treatment, day, Median (IQR) & $3(3)$ & $4.5(0)$ & 0.03 \\
\hline
\end{tabular}

ECHO: Echocardiography, EEG: Early ECHO group, LEG: Late ECHO group, SD: Standart deviation, PDA: Patent ductus arteriosus 
Table III. Long-term results of patients receiving PDA closure treatment

\begin{tabular}{|c|c|c|c|}
\hline & $\begin{array}{l}\text { EEG and receiving } \\
\text { PDA closure treatment } \\
n=17\end{array}$ & $\begin{array}{l}\text { LEG and receiving } \\
\text { PDA closure treatment } \\
n=11\end{array}$ & $p$ \\
\hline Oxygen duration, day, median (IQR) & $40(46.5)$ & $45(35)$ & 0.45 \\
\hline Discharge time, day, median(IQR) & $85(28.5)$ & $76(49)$ & 0.47 \\
\hline Respiratory distress syndrome, stage $3-4, \mathrm{n}(\%)$ & $8(47 \%)$ & $8(72.7 \%)$ & 0.27 \\
\hline Surfactant treatment, n (\%) & $15(88.2 \%)$ & $11(100 \%)$ & 0.50 \\
\hline Pulmonary hemorrhage, grade3-4 n (\%) & $4(23.5 \%)$ & $2(18.1 \%)$ & 1 \\
\hline Inotropic treatment, $\mathrm{n}(\%)$ & $9(52.9 \%)$ & $7(63.6 \%)$ & 0.57 \\
\hline Invasive mechanical ventilation, $\mathrm{n}(\%)$ & $14(82.3 \%)$ & $10(90.9 \%)$ & 1 \\
\hline Intraventricular hemorrhage, grade 3-4, n (\%) & $1(5.8 \%)$ & $1(9 \%)$ & 0.84 \\
\hline Laser requiring premature retinopathy, $\mathrm{n}(\%)$ & $7(41.1 \%)$ & $4(36.3 \%)$ & 0.79 \\
\hline Bronchopulmonary dysplasia, n (\%) & $12(70.5 \%)$ & $6(54.5 \%)$ & 0.38 \\
\hline Necrotizing enterocolitis, stage3, n (\%) & $2(11.7 \%)$ & $2(18.1 \%)$ & 1 \\
\hline Mortality, n (\%) & $2(11.7 \%)$ & $1(18.1 \%)$ & 1 \\
\hline
\end{tabular}

EEG: Early ECHO group, LEG: Late ECHO group, PDA: Patent ductus arteriosus

\section{Discussion}

There is no consensus in the literature on screening ELBWs routinely in the first 72 hours with ECHO or only performing ECHO on babies with clinical PDA symptoms. The study by Sellmer et al. reported that the presence of PDA on day 3 in ELBWs was associated with mortality and serious morbidity (14). However, some previous randomized controlled trials (RCTs) have demonstrated that later morbidities are not increased by short-term PDA exposures (for 72 hours after birth) (15-17). Nevertheless, in the Turkish Neonatology Association's guide, it is recommended that ELBWs be scanned in terms of PDA by performing ECHO in the first 2448 hours (9).

Seo et al. (18) published a retrospective study in March 2020 and they showed that hsPDA was present in 97 (74\%) of 131 patients between $23-26 \mathrm{GW}$. In our study, we found that our hsPDA rates were $37.9 \%$ in EWLB babies. The difference between hsPDA rates found in the two studies was thought to be due to the lower gestation week of the patient group in the study of Seo et al (Mean GW of two study 24.5 week/26.2 week). And also, Babla et al declare that the prevalence of PDA falls as gestational age increases, with up to $56 \%$ of infants born under 28 weeks' gestation affected (19).

Considering the demographic characteristics between the two groups in our study, the antenatal steroid rate was higher in EEG (56.5\% vs $15.3 \%)$ and the rate of patients who had hsPDA was also high in the same group (51.1\% vs $26 \%)$. We would have expected that antenatal steroids reduced hsPDA rates (20). Since this group was applied early ECHO, we think that more hsPDA was detected in patients.

In our study, we did not find any difference between the groups for ECHO findings. Sardar et al describe that early functional echocardiography on day 3 , especially the flow pattern, is useful for the prediction of PDA closure (21). Furthermore, Babla et al. (19) demonstrated that the specificity of the pulsatile flow pattern on the 24th hour, 3rd day, and 7 th day was $59 \%, 78 \%$, and $100 \%$, respectively, to predict hsPDA. In the same study, from day 1 until day 7, when combined with the presence of a murmur, the positive predictive value of increased pulse volume for hsPDA was found to be $77 \%$. In this case, the importance of clinical follow-up becomes apparent rather than performing ECHO at the first 72 hours in EWLB babies.

In the presence of hsPDA, there are different opinions about giving early medical closure treatment. The tendency to give conservative treatment has increased due to some of the reasons listed below: a) $<1000 \mathrm{~g}$ infants have $40 \%$ spontaneous closure, b) early closure treatment is related to gastrointestinal bleeding, NEC, and oliguria, c) early treatment does not cause a decrease in BPD, NEC, and neurodevelopmental morbidity $(9,22)$. On the other hand, Klukow et al. (23) in 2014, detected large PDA in $92(56.2 \%)$ of 164 babies born under $29 \mathrm{GW}, 44$ of these babies gave indomethacin and 48 placebos. There was no difference in the main outcome between groups. They showed that infants receiving early indomethacin had significantly less early pulmonary hemorrhage $(\mathrm{PH})(2 \%$ vs $21 \%)$, a trend towards less periventricular/intraventricular hemorrhage (PIVH) (4.5\% vs $12.5 \%)$, and were less likely to receive later open-label treatment for a PDA (20\% vs 40\%). In Cochrane meta-analyses, prophylactic or presymptomatic closure therapy is not recommended $(15,24)$. In our study, although there was no difference in the rates of giving treatment between the groups, it was observed that EEG was given earlier closure treatment. Early detection of hsPDA can be provocative for early treatment at the clinician. The fact that there is no difference between the long- 
term results of the patients receiving treatment suggests that it is not beneficial to give treatment in the first 72 hours.

This study has certain limitations. One of these is its retrospective nature. Furthermore, the fact that it was conducted at a single center based on a single guideline can also be considered a limitation. The most important limitation of the study is the low number of patients. However, the number of patients is low due to taking ELBWs with hsPDA as a patient group.

Conclusions: Performing early ECHO without symptoms in infants with ELBW may provoke the clinician to give PDA closure treatment earlier. In infants with ELBW, unnecessary closure treatment can be prevented by closely monitoring the symptoms of PDA and performing ECHO when necessary.

Conflict of interest statement: The authors declare no conflict of interest.

Acknowledgments: None.

Funding: None.

Authors'contributions: RC: Design, literature search, writing manuscript. SAO: and EYE: Design, supervision, CZ: and MMY: Data collection and/or processing. TGY: Data collection and/or processing, FK: and OK: Analysis and/or interpretation. SC: Supervision

This study was presented as an oral presentation by the author at the Sami Ulus PDA Multidisciplinary Approach Symposium on 13 March 2019.

\section{References}

1. Gillam-Krakauer M, Reese J. Diagnosis and management of patent ductus arteriosus. Neoreviews. 2018;19(7):e394e402. Doi: 10.1542/neo.19-7-e394.

2. Noori S, McCoy M, Friedlich P, Bright B, Gottipati V, Seri I, et al. Failure of ductus arteriosus closure is associated with increased mortality in preterm infants. Pediatrics. 2009;123(1):e138-44. Doi: 10.1542/peds. 2008-2418.

3. Havranek T, Rahimi M, Hall H, Armbrecht E. Feeding preterm neonates with patent ductus arteriosus (PDA): intestinal blood flow characteristics and clinical outcomes. J Matern Fetal Neonatal Med. 2015;28(5):52630. Doi: 10.3109/14767058.2014.923395.

4. Kaempf JW, Wu YX, Kaempf AJ, Kaempf AM, Wang L, Grunkemeier G. What happens when the patent ductus arteriosus is treated less aggressively in very low birth weight infants? J Perinatol. 2012;32(5):344-8. Doi: 10.1038/jp.2011.102.

5. Evans N, Kluckow M. Early ductal shunting and intraventricular haemorrhage in ventilated preterm infants. Arch Dis Child Fetal Neonatal Ed. 1996;75(3):183-6. Doi: 10.1136/fn.75.3.f183.

6. Kluckow M, Jeffery M, Gill A, Evans N. A randomised placebo-controlled trial of early treatment of the patent ductus arteriosus. Arch Dis Child Fetal Neonatal Ed.
2014;99(2):F99-F104. Doi: 10.1136/archdischild-2013304695.

7. Benitz WE; Committee on Fetus and Newborn, American Academy of Pediatrics. Pediatrics. 2016;137(1): e20153730. Doi: 10.1542/peds.2015-3730.

8. Koch J, Hensley G, Roy L, Brown S, Ramaciotti C, Rosenfeld CR. Prevalence of spontaneous closure of the ductus arteriosus in neonates at a birth weight of 1000 grams or less. Pediatrics. 2006;117(4):1113-21. Doi: 10.1542/peds.2005-1528.

9. Köksal N, Aygün C, Uras N. Turkish Neonatal Society guideline on the management of patent ductus arteriosus in preterm infants. Turk Pediatri Ars. 2018;53(Suppl 1):S76-S87. Doi: 10.5152/TurkPediatriArs.2018.01808.

10. Clyman RI, Liebowitz M, Kaempf J, Erdeve O, Bulbul A, Håkansson $\mathrm{S}$ et al. PDA-TOLERATE (PDA: TO LEave it alone or Respond And Treat Early) Trial Investigators. PDA-TOLERATE Trial: An exploratory randomized controlled trial of treatment of moderate-to-large patent ductus arteriosus at 1 week of age. J Pediatr. 2019;205:4148.e6. Doi: 10.1016/j.jpeds.2018.09.012.

11. Harling S, Hansen-Pupp I, Baigi A, Pesonen E. Echocardiographic prediction of patent ductus arteriosus in need of therapeutic intervention. Acta Paediatr. 2011;100(2):231-5. Doi: 10.1111/j.1651-2227.2010. 02027.x.

12. Oncel MY, Erdeve O. Oral medications regarding their safety and efficacy in the management of patent ductus arteriosus. World J Clin Pediatr. 2016;5(1):75-81. Doi: 10.5409/wjcp.v5.i1.75.

13. Oncel MY, Erdeve O. Safety of therapeutics used in management of patent ductus arteriosus in preterm infants. Current Drug Safety. 2015;10(2):106-12. Doi: 10.2174/ 1574886309999141030142847.

14. Sellmer A, Bjerre JV, Schmidt MR, McNamara PJ, Hjortdal VE, Høst B et al. Morbidity and mortality in preterm neonates with patent ductus arteriosus on day 3 . Arch Dis Child Fetal Neonatal Ed. 2013;98(6):F505-10. Doi: 10.1136/archdischild-2013-303816.

15. Cooke L, Steer P, Woodgate P. Indomethacin for asymptomatic patent ductus arteriosus in preterm infants. Cochrane Database Syst Rev. 2003;(2):CD003745. Doi: 10.1002/14651858.CD003745.

16. Fowlie PW, Davis PG, McGuire W. Prophylactic intravenous indomethacin for preventing mortality and morbidity in preterm infants. Cochrane Database Syst Rev. 2010;2010(7):CD000174. Doi: 10.1002/14651858.CD 000174.pub2.

17. Benitz WE. Treatment of persistent patent ductus arteriosus in preterm infants: time to accept the null hypothesis? J Perinatol. 2010; 30(4):241-52. Doi: 10.1038/jp.2010.3.

18. Seo ES, Sung SI, Ahn SY, Chang YS, Park WS. Changes in serum creatinine levels and natural evolution of acute 
kidney injury with conservative management of hemodynamically significant patent ductus arteriosus in extremely preterm infants at 23-26 weeks of gestation. J Clin Med. 2020;9(3):699. Doi: 10.3390/jcm9030699.

19. Babla K, Sandeep S, Kulkarni A. A clinical and echocardiographic approach to evaluation of patent ductus arteriosus in preterm infants. J Paediatr Child Health. 2020; 30(4):129-34. Doi: 10.1016/j.paed.2020.01.003.

20. Howell EA, Stone J, Kleinman LC, Inamdar S, Matseoane S, Chassin MR. Approaching NIH Guideline Recommended Care for Maternal-Infant Health: Clinical failures to use recommended antenatal corticosteroids. Matern Child Health J. 2010;14(3):430-6. Doi: 10.1007/s10995009-0480-3.

21. Sardar SK, Saha AK, Majhi B, Chatterjee S. Prediction of ductus closure and development of adverse clinical outcome by functional echocardiography in very low birth weight newborn. J Neonatal Perinatal Med. 2020;13(1): 31-7. Doi: 10.3233/NPM-190229.

22. Bell EF, Acarregui MJ. Restricted versus liberal water intake for preventing morbidity and mortality in preterm infants. Cochrane Database of Systematic Reviews 2014; 2014(12):CD000503. Doi: 10.1002/14651858.CD000 503.pub3.

23. Kluckow M, Jeffery M, Gill A, Evans N. A randomised placebo-controlled trial of early treatment of the patent ductus arteriosus. Arch Dis Child Fetal Neonatal Ed. 2014;99(2):F99-F104. Doi: 10.1136/archdischild-2013304695 .

24. Ohlsson A, Shah SS. Ibuprofen for the prevention of patent ductus arteriosus in preterm and/or low birth weight infants. Cochrane Database Syst Rev. 2020;1(1): CD004213. Doi: 10.1002/14651858.CD004213.pub5. 